\title{
Pflegekammern im europäischen Kontext
}

\author{
Heinrich Hanika
}

(C) Springer-Verlag 2012

In Verantwortung für die Gesundheit der europäischen Bevölkerung wird seitens des Rates der Europäischen Union eine patientenorientierte Gesundheitspolitik für Europa als eine bereichsübergreifende Herausforderunganerkannt. Das 21. Jahrhundert wird als das ,Jahrhundert der Gesundheitsversorgung" charakterisiert.

Die Träger funktionaler Selbstverwaltung - wie Pflegekammern - übernehmen wichtige Ordnungsfunktionen im Binnenmarkt, vor allem durch das von ihnen entwickelte Berufsrecht und Berufsethos. Sie verhindern die Flucht in die Anonymität, die oft die Grundlage für rechtsmissbräuchliche Praktiken darstellt. Schließlich dienen das von den Selbstverwaltungskörperschaften erlassene Berufsrecht und die von ihnen ausgeübte Berufsaufsicht in vielfältiger Hinsicht dem Schutz der Verbraucher.

Der Europäische Gerichtshof (EuGH) hat ausdrücklich betont, dass die Rechtsvorschriften der Mitgliedstaaten, die die Pflichtmitgliedschaft in einer berufsständischen Kammer vorschreiben, als solche mit dem Gemeinschaftsrecht vereinbar sind (EuGH, Urt. v. 22.9.1983 - Rs 271/82). Europaweit kann eine Verwurzelung der Pflege im Demokratieprinzip sowie im Leitgedanken der Dezentralisation festgestellt werden, der sich in den Mitgliedstaaten zunehmend aktualisiert.

In Europa existiert eine Vielzahl von Vorbildern für die berufliche Selbstverwaltung der Pflege. Auch in den letzten Jahren sind Pflegekammern neu entstanden, wie z. B. 1998 in Portugal oder 2002 in der Slowakei. Hierbei erhielten die Kammern auch bedeutende Aufgaben und Zuständigkeiten zugewiesen, die den Professionalisierungsgrad der Pflege in vielen Ländern gegenüber Deutschland beachtlich fort-

H. Hanika $(\square)$

Universities of Berlin, Budapest, Ludwigshafen, Deutschland schreiten ließen. Viele Kammern wurden infolgedessen zu Garanten der pflegerischen Versorgung der Bevölkerung.

Die Einführung von Pflegekammern wäre ein vorteilhafter und zeitgemäßer Schritt in die Zukunft für die Pflege, insbesondere um den Berufsangehörigen demokratische Partizipationsmöglichkeiten zu eröffnen sowie den sich abzeichnenden Pflegekollaps zu vermeiden. 